\title{
Breast cancer metastases to the thyroid gland - an uncommon sentinel for diffuse metastatic disease: a case report and review of the literature
}

\author{
Agata M. Plonczak ${ }^{1 *}$, Aimee N. DiMarco ${ }^{1}$, Roberto Dina ${ }^{2}$, Dorothy M. Gujral ${ }^{3}$ and Fausto F. Palazzo ${ }^{1}$
}

\begin{abstract}
Background: Metastases to the thyroid are rare. The most common primary cancer to metastasize to the thyroid is renal cell carcinoma, followed by malignancies of the gastrointestinal tract, lungs, and skin, with breast cancer metastases to the thyroid being rare. Overall, the outcomes in malignancies that have metastasized to the thyroid are poor. There are no prospective studies addressing the role of surgery in metastatic disease of the thyroid. Isolated thyroidectomy has been proposed as a local disease control option to palliate and prevent the potential morbidity of tumor extension related to the airway. Here, we present a case of a patient with breast cancer metastases to the thyroid gland and discuss the role of thyroidectomy in the context of the current literature.
\end{abstract}

Case presentation: A 62-year-old Afro-Caribbean woman was diagnosed as having bilateral breast carcinoma in 2004, for which she underwent bilateral mastectomy. The pathology revealed multifocal disease on the right, T2NO(0/20)M0 grade 1 and 2 invasive ductal carcinoma, and on the left side, T3N1(2/18)M0 grade 1 invasive ductal carcinoma. Surgery was followed by adjuvant chemotherapy and regional radiotherapy. The disease was under control on hormonal therapy until 2016, when she developed cervical lymphadenopathy. The fine-needle aspiration cytology of the thyroid was reported as papillary thyroid cancer; and the fine-needle biopsy of the left lateral nodal disease was more suggestive of breast malignancy. She underwent a total thyroidectomy and a clearance of the central compartment lymph nodes and a biopsy of the lateral nodal disease. The histopathological analysis was consistent with metastatic breast cancer in the thyroid and lymph nodes with no evidence of a primary thyroid malignancy.

Conclusions: A past history of a malignancy elsewhere should raise the index of suspicion of metastatic disease in patients presenting with thyroid lumps with or without cervical lymphadenopathy. Detection of metastases to the thyroid generally indicates poor prognosis, obviating the need of surgery in an already compromised patient. An empirical thyroidectomy should be considered in select patients for local disease control.

Keywords: Thyroid disorders, Breast cancer, Clinical oncology, Endocrine surgery

\footnotetext{
* Correspondence: agata.plonczak@gmail.com

${ }^{1}$ Department of Thyroid \& Endocrine Surgery, Hammersmith Hospital,

Imperial College Hospitals NHS Trust, London W12 OHS, UK

Full list of author information is available at the end of the article
} 


\section{Background}

Breast cancer is the most commonly diagnosed cancer among women [1]. The common sites for metastatic spread are bone, lungs, and liver [2]. Metastases to the thyroid gland from a non-thyroid primary are uncommon and are mostly from the kidney, followed by gastrointestinal tract, lungs, skin, and rarely breast [3-7]. It is usually associated with a poor prognosis. There are no prospective studies addressing the role of surgery in metastatic disease of the thyroid. Isolated thyroidectomy has been proposed as a local disease control option to palliate and prevent the potential morbidity of tumor extension related to the airway. Here, we present a rare case of a patient with breast cancer metastases to the thyroid gland, and review the evidence for the role of thyroidectomy in the context of the current literature.

\section{Case presentation}

A 62-year-old Afro-Caribbean woman was diagnosed as having bilateral carcinoma of the breast in 2004. Her past medical history included hypertension, controlled by amlodipine and losartan, in addition to diabetes on treatment with metformin. She underwent bilateral mastectomy and axillary node clearance with immediate implant-based reconstruction. The pathology revealed multifocal disease on the right, T2N0 $(0 / 20) \mathrm{M} 0$ grade 1 and 2 invasive ductal carcinoma (IDC), and on the left side, T3N1(2/18)M0 grade 1 IDC. The disease was estrogen receptor (ER)-positive, weak progesterone receptor (PR)-positive, and human epidermal growth factor receptor 2 (HER2)-negative. Surgery was followed by adjuvant chemotherapy, consisting of the 5-fluorouracil, epirubicin, and cyclophosphamide (FEC) regimen and regional radiotherapy. Hormonal therapy initially consisted of $20 \mathrm{mg}$ daily of tamoxifen. After 3 years this was switched to an aromatase inhibitor (anastrozole $1 \mathrm{mg}$ daily) until 2009 when she completed 5 years of adjuvant endocrine therapy. She then subsequently relapsed with metastatic disease with lung nodules in 2008 and bone metastases were noted on a bone scan 4 years later. She was commenced on $25 \mathrm{mg}$ once a day of exemestane and $4 \mathrm{mg}$ intravenously administered monthly injections of zoledronic acid in early 2014. Due to disease progression, capecitabine $1250 \mathrm{mg} / \mathrm{m}^{2}$ (based on total body surface area) twice daily was commenced until after six cycles when it was discontinued due to capecitabinerelated toxicity and she was started on $2.5 \mathrm{mg}$ once a day of letrozole and $150 \mathrm{mg}$ once a day of ibandronic acid. In February 2016 she presented with neck swelling with intermittent neck discomfort without airway pressure symptoms. On clinical examination she was found to have cervical lymphadenopathy. Laboratory findings revealed a white cell count of $5.2 \times 10^{9} / \mathrm{L}$, hemoglobin of $115 \mathrm{~g} / \mathrm{L}$, and normal liver and renal function with an estimated glomerular filtration rate of $67 \mathrm{ml} / \mathrm{minute} /$ $1.73 \mathrm{~m}^{2}$. The neck swelling was investigated with an ultrasound and confirmed both lateral cervical nodal disease in levels II to IV and a goiter with left-sided dominance. The fine-needle aspiration cytology (FNAC) of her thyroid was reported as in keeping with a papillary thyroid cancer; however, the cytology of the left lateral nodal disease was described as more suggestive of a breast malignancy. She had no personal or familial risk factors for thyroid malignancy. Staging investigations including magnetic resonance imaging (MRI) of her spine demonstrated stable deposits involving C2, C5, T4, and L1 without neural compromise (Fig. 1) and computed tomography $(\mathrm{CT})$ of her thorax demonstrated no change in the lung nodules (Fig. 2). Since the diagnosis was not clear, following a multidisciplinary team discussion the decision was made to proceed with a total thyroidectomy and a clearance of the central compartment lymph nodes coupled with an excision biopsy of the laterocervical lymph nodes. Histopathological analysis of the specimen demonstrated an ill-circumscribed white tumor at the posterior margin of the left lobe measuring $1.2 \times 0.9 \times 1.5 \mathrm{~cm}$. On immunocytochemistry the tumor cells were positive for carcinoembryonic antigen (CEA), synaptophysin, GATA3, and ER (5/8), focally positive for cytokeratin (CK) 7 and gross cystic disease fluid protein 15 (GCDFP-15), and

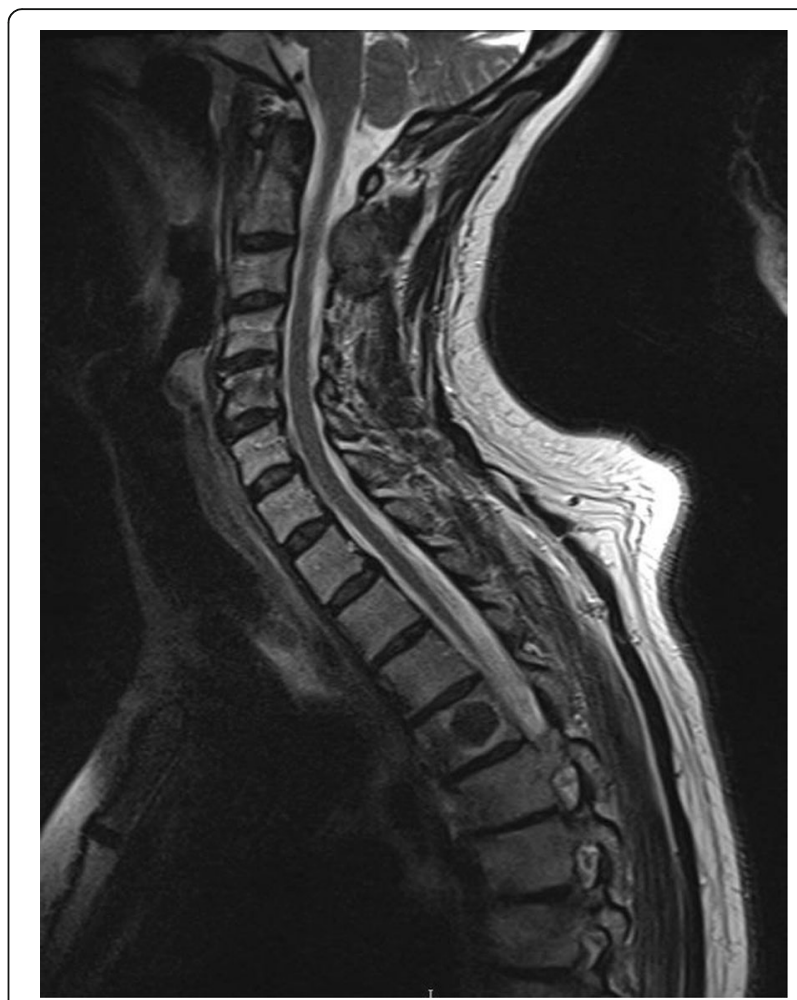

Fig. 1 T2-weighted sagittal magnetic resonance image demonstrating the deposits in C5 and T4. They appeared confined to the vertebral body with no evidence of vertebral body collapse 


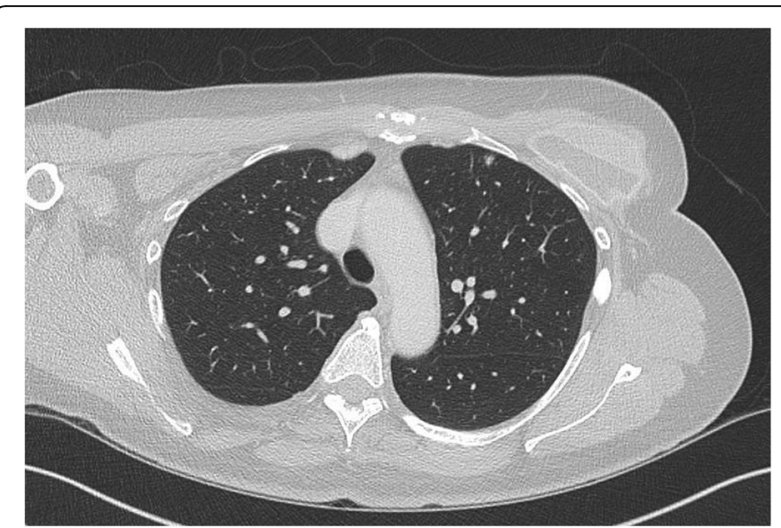

Fig. 2 Computed tomography of the thorax demonstrating a small (5 $\mathrm{mm}$ in diameter) subpleural nodule within the anterior left upper lobe, which remained unchanged since the previous scan

negative for thyroid transcription factor 1 (TTF-1), calcitonin, thyroglobulin, CK20, PR, and HER2. The overall appearances were consistent with metastatic breast cancer (Figs. 3 and 4) with no evidence of a primary thyroid malignancy. The level IV and level VI lymph nodes contained metastatic breast cancer. She was discharged on daily $125 \mathrm{mcg}$ of levothyroxine. The chemotherapy was switched to $500 \mathrm{mg}$ intramuscular monthly injections of fulvestrant and she continues to take the ibandronic acid. Currently, 14 months following the thyroidectomy, she remains clinically stable. She developed local recurrences in the level II to IV lymph nodes in her neck and a recent MRI of her spine showed stable spinal metastatic disease.

\section{Discussion}

Metastatic deposits have a predilection for highly vascularized organs but despite one of the highest blood supplies per weight of tissue (4 to $6 \mathrm{~mL} / \mathrm{minute} / \mathrm{g}$ ) [8]

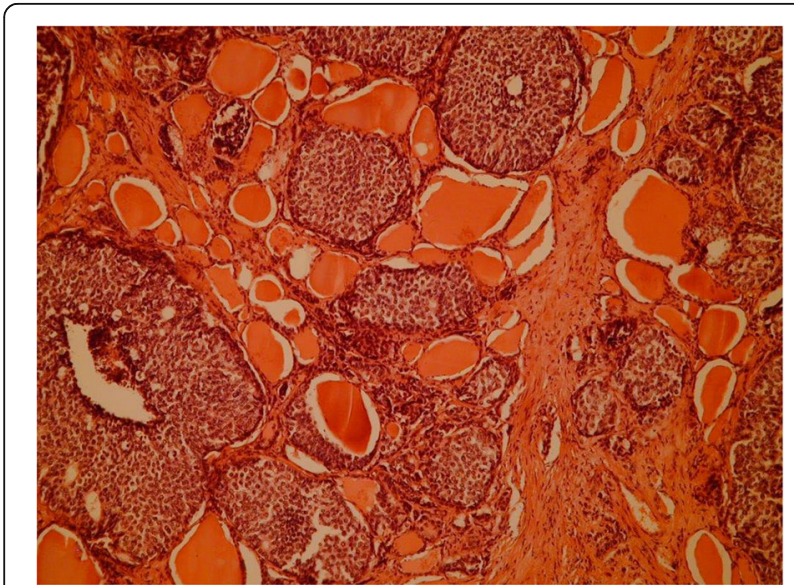

Fig. 3 Hematoxylin and eosin stain at $\times 100$ magnification demonstrating solid nests of atypical epithelial cells among normal colloid-filled thyroid follicles

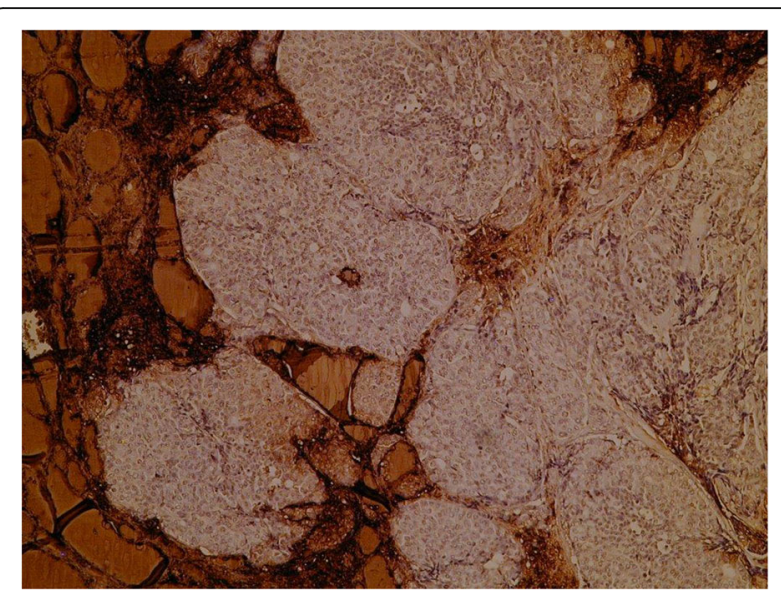

Fig. 4 Immunoperoxidase for thyroglobulin showing the solid nests, which are negative while the follicles are positive, including a small trapped microfollicle within the larger nest of metastatic cells. Thyroid transcription factor 1 and calcitonin were equally negative; however, cytokeratin 7 was focally positive and synaptophysin was expressed by the majority of cells. This raises the possibility of a carcinoma with neuroendocrine features

the thyroid is rarely the site for metastatic deposits. It is difficult to establish the true rate of metastases from breast cancer to the thyroid gland with a quoted range of prevalence from 3\% of all thyroid metastases [4] to $34 \%$ (Table 1) [3, 4, 6, 7, 9-27]. Metastases to the thyroid gland represent an indication for surgery in under 1 in a 1000 thyroidectomies [24, 28] of which almost half are from a renal cell carcinoma primary $[7,29]$. Other primary tumors that have been documented to metastasize to the thyroid include colorectal, lung, and malignant melanoma [3-7] and gastrointestinal tract tumors [10].

Breast cancer is the most common malignant tumor among women [1]; while being uncommon, thyroid cancers are the most common endocrine malignancies and the incidence is rising [30]. It has been suggested that possibly due to some common risk factors (genetic, lifestyle, diet habits, hormonal, menstrual, and reproductive factors), individuals with breast cancer are more likely to develop primary thyroid cancer [31, 32]. Therefore, an individual presenting with both thyroid and breast malignancy is more likely to have primary cancer of thyroid and breast, rather than breast metastases to the thyroid.

Up to $80 \%$ of thyroid metastases are metachronous [29] with mean intervals from as little as 2.3 years in head and neck cancer $[7,21]$ to as long as 21 years in the case of foregut neuroendocrine tumors [33]. Other metachronous tumors present varying levels of delay with a mean of 9.4 years in renal cell carcinoma primaries [34] and 48.2 months [29] in breast primary malignancies. Longer delays in metachronous tumors probably reflect a less aggressive biology and in fact the 
Table 1 Clinical studies (case reports and case series) of breast metastases to the thyroid gland published so far

\begin{tabular}{llll}
\hline Author & Study years & $\begin{array}{l}\text { Number of } \\
\text { patients }\end{array}$ & $\begin{array}{l}\text { Percentage of thyroid } \\
\text { metastases from breast }\end{array}$ \\
\hline Harcourt-Webster [9] & - & 2 & $18 \%$ \\
Lam and Lo [10] & - & 7 & $9 \%$ \\
Mayo and Schlicke [11] & - & 2 & $11 \%$ \\
Elliott and Frantz [12] & $1947-1958$ & 4 & $29 \%$ \\
Wychulis et al. [13] & $1907-1962$ & 4 & $29 \%$ \\
Pillay et al. [14] & $1974-1976$ & 1 & $10 \%$ \\
Lin et al. [15] & $1977-1995$ & 1 & $7 \%$ \\
Chacho et al. [16] & $1978-1985$ & 1 & $13 \%$ \\
Rosen et al. [17] & $1978-1993$ & 1 & $9 \%$ \\
Hegerova et al. [7] & $1980-2010$ & 11 & $11 \%$ \\
De Ridder et al. [18] & $1982-2002$ & 1 & $17 \%$ \\
Russell et al. [19] & $1983-2013$ & 2 & $12 \%$ \\
Cichon et al. [20] & $1984-2003$ & 1 & $6 \%$ \\
Nakhjavani et al. [21] & $1985-1994$ & 7 & $16 \%$ \\
Wood et al. [22] & $1985-2002$ & 1 & $7 \%$ \\
HooKim et al. [6] & $1986-2013$ & 3 & $11 \%$ \\
Saito et al. [23] & $1987-2008$ & 3 & $34 \%$ \\
Papi et al. [24] & $1993-2003$ & 5 & $14 \%$ \\
Moghaddam et al. [3] & $1993-2013$ & 1 & $10 \%$ \\
Calzolari et al. [25] & $1995-2005$ & 1 & $4 \%$ \\
Kim et al. [26] & $1997-2004$ & 5 & $23 \%$ \\
Surov et al. [4] & $1997-2013$ & 1 & $3 \%$ \\
Choi et al. [27] & $2001-2013$ & 7 & $15 \%$ \\
\hline & & &
\end{tabular}

rarer synchronous metastases to the thyroid are associated with a much poorer prognosis with a mean 5-year survival rate of $7.9 \%$ [35].

Most reports of metastases to the thyroid are solitary with Surov and colleagues [4] reporting that thyroid metastases were solitary in $76 \%$ of patients in their study. However, Hegerova et al. [7] reported that 79\% of their patients had evidence of other metastases at the time of diagnosis of thyroid metastases, which may suggest that the extent of investigations plays a part in determining the identification of other disease.

FNAC is the investigation of choice in the work-up of thyroid nodules. It has been shown to achieve an accuracy of over $90 \%$ in the diagnosis of secondary tumors of the thyroid [36]. Unfortunately, as in the case presented, metastatic ductal breast carcinoma involving the thyroid may morphologically mimic primary thyroid malignancy on fine-needle aspiration (FNA) and secondary malignancies of the thyroid may be misdiagnosed.

Outcomes in metastatic thyroid disease tend to be poor since it is a reflection of the aggression and advanced stage of the primary disease $[5,15]$. A Mayo
Clinic series demonstrated that the mean survival post diagnosis of metastases to the thyroid is 3 years and 6 years from the original diagnosis of a primary malignancy [7].

There are no prospective studies addressing the role of surgery in metastatic disease of the thyroid. Our patient with breast metastasis to the thyroid and coexisting lung and bone metastatic deposits, was managed with a total thyroidectomy with a good outcome. Isolated thyroidectomy has been proposed in previous studies [20,37] as a local disease control option to palliate and prevent the potential morbidity of tumor extension related to the airway [37]. It has been also suggested that this may be beneficial for a selected group of patients with clinically significant and relatively isolated metastatic disease of the thyroid especially from a renal primary [25]; however, in the absence of prospective trials this is at best speculative.

\section{Conclusions}

A past history of a malignancy elsewhere should raise the index of suspicion of metastatic disease in patients presenting with thyroid lumps with or without cervical lymphadenopathy. Detection of metastases to the thyroid generally indicates poor prognosis, obviating the need of surgery in an already compromised patient. An empirical thyroidectomy should be considered in select patients for local disease control.

Acknowledgements

Not applicable.

Funding

Not applicable.

\section{Availability of data and materials}

Data sharing is not applicable to this article as no datasets were generated or analyzed during the current study.

Authors' contributions

AP drafted the manuscript. AD contributed to the literature search, wrote parts, and revised the first draft of the manuscript. DG is the oncologist of the patient, who provided and wrote the information regarding medical management. RD provided the histopathological images and analysis. FP is the consultant of the patient, who carried out the thyroidectomy and revised the draft of the manuscript. All authors read and approved the final manuscript.

Ethics approval and consent to participate Not applicable.

\section{Consent for publication}

Written informed consent was obtained from the patient for publication of this case report and any accompanying images. A copy of the written consent is available for review by the Editor-in-Chief of this journal.

Competing interests

The authors declare that they have no competing interests.

\section{Publisher's Note}

Springer Nature remains neutral with regard to jurisdictional claims in published maps and institutional affiliations. 


\section{Author details}

'Department of Thyroid \& Endocrine Surgery, Hammersmith Hospital, Imperial College Hospitals NHS Trust, London W12 OHS, UK. ${ }^{2}$ Department of Histopathology, Hammersmith Hospital, Imperial College Hospitals NHS Trust, London W12 OHS, UK. ${ }^{3}$ Department of Oncology, Charing Cross Hospital, Imperial College Hospitals NHS Trust, London W6 8RF, UK.

Received: 3 March 2017 Accepted: 29 August 2017

Published online: 22 September 2017

\section{References}

1. Siegel RL, Miller KD, Jemal A. Cancer statistics. CA Cancer J Clin. 2016;66:7-30

2. Weigelt B, Peterse JL, van't Veer LJ. Breast cancer metastasis: markers and models. Nat Rev Cancer. 2005;5:591-602.

3. Moghaddam PA, Cornejo KM, Khan A. Metastatic carcinoma to the thyroid gland: a single institution 20-year experience and review of the literature. Endocr Pathol. 2013;24:116-24.

4. Surov A, Machens A, Holzhausen HJ, Spielmann RP, Dralle H. Radiological features of metastases to the thyroid. Acta Radiol. 2016;57:444-50.

5. Mirallié E, Rigaud J, Mathonnet M, Gibelin H, Regenet N, Hamy A, Bretagnol F, de Calan L, Le Néel JC, Kraimps JL. Management and prognosis of metastases to the thyroid gland. J Am Coll Surg. 2005;200:203-7.

6. HooKim K, Gaitor J, Lin O, Reid MD. Secondary tumors involving the thyroid gland: A multi-institutional analysis of 28 cases diagnosed on fine-needle aspiration. Diagn Cytopathol. 2015;43:904-11.

7. Hegerova L, Griebeler ML, Reynolds JP, Henry MR, Gharib H. Metastasis to the thyroid gland: report of a large series from the Mayo Clinic. Am J Clin Oncol. 2015;38:338-42

8. Salvatore D, Davies T, Schlumberger MJ, Hay ID, Larsen RP. Thyroid Physiology and Diagnostic Evaluation of Patients with Thyroid Disorders. In: Melmed S, Polonsky KS, Larsen RP, et al., editors. Williams Textbook of Endocrinology. Philadelphia: Elsevier; 2016. p. 334-68.

9. Harcourt-Webster JN. Secondary neoplasm of the thyroid presenting as a goitre. J Clin Pathol. 1965;18:282-7.

10. Lam KY, Lo CY. Metastatic tumors of the thyroid gland: a study of 79 cases in Chinese patients. Arch Pathol Lab Med. 1998;122:37-41.

11. Mayo CW, Schlicke CP. Exogenous tumors of the thyroid gland. Am J Pathol. 1941;17:283-8.

12. Elliott Jr RH, Frantz VK. Metastatic carcinoma masquerading as primary thyroid cancer: a report of authors' 14 cases. Ann Surg. 1960;151:551-61.

13. Wychulis AR, Beahrs OH, Woolner LB. Metastasis of carcinoma to the thyroid gland. Ann Surg. 1964;160:169-77.

14. Pillay SP, Angorn IB, Baker LW. Tumour metastasis to the thyroid gland. S Afr Med J. 1977:51:509-12.

15. Lin JD, Weng HF, Ho YS. Clinical and pathological characteristics of secondary thyroid cancer. Thyroid. 1998:8:149-53.

16. Chacho MS, Greenebaum E, Moussouris HF, Schreiber K, Koss LG. Value of aspiration cytology of the thyroid in metastatic disease. Acta Cytol. 1987:31:705-12

17. Rosen IB, Walfish PG, Bain J, Bedard YC. Secondary malignancy of the thyroid gland and its management. Ann Surg Oncol. 1995:2:252-6.

18. De Ridder M, Sermeus AB, Urbain D, Storme GA. Metastases to the thyroid gland-a report of six cases. Eur J Intern Med. 2003;14:377-9.

19. Russell JO, Yan K, Burkey B, Scharpf J. Nonthyroid metastasis to the thyroid gland: case series and review with observations by primary pathology. Otolaryngol Head Neck Surg. 2016;155:961-8.

20. Cichon S, Anielski R, Konturek A, Barczyński M, Cichon W. Metastases to the thyroid gland: seventeen cases operated on in a single clinical center. Langenbecks Arch Surg. 2006;391:581-7.

21. Nakhjavani MK, Gharib H, Goellner JR, van Heerden JA. Metastasis to the thyroid gland. A report of 43 cases. Cancer. 1997;79:574-8.

22. Wood K, Vini L, Harmer C. Metastases to the thyroid gland: the Royal Marsden experience. Eur J Surg Oncol. 2004;30:583-8.

23. Saito Y, Sugitani I, Toda K, Yamada K, Fujimoto Y. Metastatic thyroid tumors: ultrasonographic features, prognostic factors and outcomes in 29 cases. Surg Today. 2014;44:55-61.

24. Papi G, Fadda G, Corsello SM, Corrado S, Rossi ED, Radighieri E, Miraglia A, Carani C, Pontecorvi A. Metastases to the thyroid gland: prevalence, clinicopathological aspects and prognosis: a 10-year experience. Clin Endocrinol (Oxf). 2007;66:565-71.

25. Calzolari F, Sartori PV, Talarico C, Parmeggiani D, Beretta E, Pezzullo L, Bovo G, Sperlongano P, Monacelli M, Lucchini R, Misso C, Gurrado A, D'Ajello M,
Uggeri F, Puxeddu E, Nasi P, Testini M, Rosato L, Barbarisio A, Avenia N. Surgical treatment of intrathyroid metastases: preliminary results of a multicentric study. Anticancer Res. 2008;28:2885-8.

26. Kim TY, Kim WB, Gong G, et al. Metastasis to the thyroid diagnosed by fineneedle aspiration biopsy. Clin Endocrinol (Oxf). 2005;62:236-41.

27. Choi $\mathrm{SH}, \mathrm{Baek} \mathrm{JH}, \mathrm{Ha} \mathrm{EJ}$, et al. Diagnosis of metastasis to the thyroid gland: comparison of core-needle biopsy and fine-needle aspiration. Otolaryngol Head Neck Surg. 2016;154:618-25.

28. Diaconescu MR, Costea I, Glod M, Grigorovici M, Diaconescu S. Unusual malignant tumors of the thyroid gland. Chirurgia. 2013;108:482-9.

29. Chung AY, Tran TB, Brumund KT, Weisman RA, Bouvet M. Metastases to the thyroid: a review of the literature from the last decade. Thyroid. 2012;22:258-68.

30. Zamora-Ros $\mathrm{R}$, et al. Reproductive and menstrual factors and risk of differentiated thyroid carcinoma: The EPIC study. Int J Cancer. 2015;136:1218-27.

31. Joseph KR, Edirimanne S, Eslick GD. The association between breast cancer and thyroid cancer: a meta-analysis. Breast Cancer Res Treat. 2015;152:173-81.

32. Fei X, Christakos G, Lou Z, Ren Y, Liu Q, Wu J. Spatiotemporal Co-existence of Female Thyroid and Breast Cancers in Hangzhou, China. Sci Rep. 2016;6:2-11.

33. Mattavelli F, Collini P, Pizzi N, Gervasoni C, Pennacchioli E, Mazzaferro V. Thyroid as a target of metastases. A case of foregut neuroendocrine carcinoma with multiple abdominal metastases and a thyroid localization after 21 years. Tumori. 2008:94:110-3.

34. Heffess CS, Wenig BM, Thompson LD. Metastatic renal cell carcinoma to the thyroid gland: a clinicopathologic study of 36 cases. Cancer. 2002;95:1869-78.

35. Chen JY, Chen IW, Hsueh C, Chao TC, Gao BR, Lin JD. Synchronous diagnosis of metastatic cancer to the thyroid is associated with poor prognosis. Endocr Pathol. 2015;26:80-6.

36. Aron M, Kapila K, Verma K. Role of fine-needle aspiration cytology in the diagnosis of secondary tumors of the thyroid - twenty years' experience. Diagn Cytopathol. 2006;34:240-5.

37. Chen $\mathrm{H}, \mathrm{Nicol} \mathrm{TL}$, Udelsman R. Clinically significant, isolated metastatic disease to the thyroid gland. World J Surg. 1999;23:177-80

\section{Submit your next manuscript to BioMed Central and we will help you at every step:}

- We accept pre-submission inquiries

- Our selector tool helps you to find the most relevant journal

- We provide round the clock customer support

- Convenient online submission

- Thorough peer review

- Inclusion in PubMed and all major indexing services

- Maximum visibility for your research

Submit your manuscript at www.biomedcentral.com/submit 